\title{
In Vitro and In Vivo anticancer activity of Ferula gummosa essential oil nanoemulsions (FGEO-NE) for the colon cancer treatment
}

\section{Toktam Nosrat}

Department Of Biology, Mashhad Branch, Islamic Azad University, Mashhad, Iran Masoud Homayouni Tabrizi ( $\nabla$ mhomayouni6@gmail.com)

Department of Biology, Mashhad Branch, Islamic Azad University, Mashhad, Iran https://orcid.org/0000-0002-5078-9973

\section{Ayda Etminan}

Department of Biology, Mashhad Branch, Islamic Azad University, Mashhad, Iran

\section{Mahjoubeh Irani}

Department Of Biology, Mashhad Branch, Islamic Azad University, Mashhad, Iran

\section{Bahar Zarei}

Department of Biology, Mashhad Branch, Islamic Azad University, Mashhad, Iran

\section{Amir Rahmati}

Department of Biology, Mashhad Branch, Islamic Azda University, Mashhad, Iran

\section{Research Article}

Keywords: Ferula gummosa essential oil, Nano emulsion, apoptosis, cytotoxic, antiangiogenic, anti-tumor

Posted Date: February 11th, 2022

DOI: https://doi.org/10.21203/rs.3.rs-1324811/v1

License: (c) (i) This work is licensed under a Creative Commons Attribution 4.0 International License. Read Full License 


\section{Abstract}

This survey was performed to aim of synthesize Nano emulsion from Ferula gummosa essential oil (FEGO-NE) and to evaluate its anti-tumor effect.

First, Ferula gummosa essential oil was analyzed by GC-MS method, then the Nano emulsion was synthesized as O/W and after characterization by DLS, Zeta potential, AFM, FESEM and TEM methods, its toxicity was evaluated by MTT method. Then its pro-apoptotic effects were evaluated by qPCR (Caspase3, 9, Bax and Bcl-2) method and AO/PI staining. The cancer induction model was used to evaluate the antitumor effects in Balb/C mice. The anti-angiogenic and antioxidant effects were evaluated by qPCR (VEGF, CAT and SOD) method.The results of physicochemical studies showed the formation of nanoparticles with dimensions of $24.6 \mathrm{~nm}$, dispersion index of 0.41 and zeta potential of $-28.5 \mathrm{mV}$ with a spherical morphology. The Nano emulsion synthesized at a concentration of $2.9 \mu \mathrm{g} / \mathrm{ml}$ inhibited about $50 \%$ of ht-29 cells, while up to a concentration of $4 \mu \mathrm{g} / \mathrm{ml}$ showed no inhibitory effect on normal cells. Increase of caspase 3, 9 and Bax and decrease of BCL-2 gene expression along with increase of apoptotic cells in AP / PI staining confirmed induction of apoptosis by FEGO-NE. The FEGONE showed an inhibitory effect on angiogenesis and an additive effect on the expression of antioxidant genes. In addition, the reduction of tumor volume (69.72\% in 14 days) in samples treated with FEGO-NE was confirmed. The results of this study showed that FEGO-NE by various mechanisms are able to inhibit cancer cells and have a reducing effect on induced tumors in the in vivo model. These results suggest FEGO-NE as a suitable candidate for cancer therapy studies.

\section{Introduction}

Cancer is a deadly multifactorial disease that begins with the uncontrolled growth of cells and invades surrounding cells and tissues, leading to tumor formation and spread (Kosmo 2017). Lack of diagnostic techniques and standard treatment methods lead to the mortality increase due to this disease. The most common current treatment is the use of chemical drugs; however, these drugs are designed to target cells with high proliferation rates and are unable to differentiate cancer cells from normal cells with high proliferation rates. This can lead to some irreversible side effects (Gautam et al. 2014). Gradual resistance of cancer cells to treatment is one of the most important problems in common cancer treatments (chemotherapy and radiotherapy). Therefore, the development of new therapies is one of the goals of immunopharmacological studies in order to increase the effectiveness of treatment (Azadmehr et al. 2011).

Effective strategies for targeting cancer cells include induction of apoptosis, cell cycle inhibition, and angiogenesis, so natural products with such capabilities are valuable resources in suppressing cancer (Gautam et al. 2014). Bioactive compounds act through various mechanisms such as disruption of cellular signal transduction pathways, cell cycle change, interference with microtubules, and topoisomerase inhibitors (Nobili et al. 2009). Also, some studies have reported the anti-angiogenic effects 
and antioxidant power of some phytochemical compounds such as flavonoids, polyphenolic acids, phenolic diterpenes, catechols and tannins, etc (Kadioglu et al. 2013).

Among plant-derived compounds, essential oils (EO) have anti-cancer properties. Although treatment with these compounds cannot replace chemotherapy and radiotherapy, it can be used in combination with cancer therapy to reduce the side effects of medications. Hence, such compounds can be used to improve the health of patients and as a source of new anticancer compounds (Mitoshi et al. 2012). Essential oils contain 20 to 60 low molecular weight compounds (alkaloids, phenols and terpenes) that introduced by the FDA (FDA) and the EPA (Environmental Protection Agency) as GRAS (generally safe) substances(Benelli et al. 2017). Despite the high therapeutic effects, the susceptibility of these compounds to various chemical reactions, such as oxidation, causes instability and reduces or eliminates their effectiveness(Pavoni et al. 2020). Other functional limitations of essential oils included their poor physical and chemical properties, including lack of solubility in water (lipophilic compounds of essential oils), high fluctuations and their rapid half-life noted (Pavoni et al. 2019a).

Nanocapsulation technology is one of the promising approaches for transporting and loading essential oils. The nanometer dimensions of these carriers cause the penetration of bioactive compounds into deeper tissues and increase their cellular uptake. In addition to increasing biological activity, they provide the possibility of controlling and modulating the release of active substances in the desired location. Finally, such an approach can increase solubility and reduce fluctuations and protect of bioactive compound in interaction with the environment (Perlatti et al. 2013). There are various strategies such as preparation of polymer, metal and lipid nanoparticles (liposomes and solid lipid nanoparticles and micro and nanoemulsions) for the formulation of bioactive compounds that among which, nanomulsions are the simplest and least expensive way to formulate fat-soluble compounds (Pavoni et al. 2019b).

In this study, Ferula gummosa essential oil (FGEO) was used due to its phytochemical components. This essential oil contains terpenoids such as a-pinene, which are known to be anti-cancer compounds (Mahboubi 2016). The presence of hydrophobic and non-polar active compounds in this essential oil definitely reduces its solubility and thus its bioavailability. Therefore, to improve the bioavailability, this essential oil was encapsulated by amphiphilic molecules and formulated as a nanoemulsion (Nishitani Yukuyama et al. 2017). The overall purpose of this study was to synthesize nanoemulsions from Ferula gummosa (Barijeh) essential oil to increase bioavailability and to evaluate its anti-cancer effects.

\section{Materials And Methods}

\section{Material}

The Ferula gummosa essential oil (FGEO) and Tween 80 (T-80) were purchased from Merck Co. The RPMI and DMEM cell culture medium, Streptomycin/Penicillin, FBS (Fetal Bovine serum), tetrazolium dye MTT 3-(4,5-dimethylthiazol-2-yl)-2,5-diphenyltetrazolium bromide, and dimethylsulfoxide (DMSO) were purchased from Sigma Aldrich. The human colon cancer (HT-29) and normal (HFF) cell lines were provided from Cell Bank of Ferdowsi University of Mashhad, Iran. 


\section{GC-MS analysis}

Gas chromatography-mass spectrometry (GC-MS; Agilent Technologies, Santa Clara, CA, USA) were used to analyze the FGEO components. The transfer line temperature and ion-source temperature were $250^{\circ} \mathrm{C}$ and $200^{\circ} \mathrm{C}$, respectively. The temperature program was set at $60^{\circ} \mathrm{C}(1 \mathrm{~min})$ and $220^{\circ} \mathrm{C}(15 \mathrm{~min})$ and the heating rate was set at $5^{\circ} \mathrm{C} / \mathrm{min}$. The scan-range was $40-450$ amu with a cycle time of $0.25 \mathrm{sec}$.

\section{FGEO-NE emulsification}

In order to achieve the optimal formulation, in this study, different volumes of Tween $80(6,12$, and 18 $\mathrm{mL})$ were used as surfactants. First, essential oil $(3 \mathrm{ml})$ was added to the desired volume of surfactant and then deionized distilled water was added to the solution (until the final volume of $100 \mathrm{~mL}$ ). The ultrasonic waves (hielscher-UP400-24 kHz, Germany) at 150-watt and 20kHz frequency were utilized for 2 minutes to optimize the emulsification (Shafaei et al. 2020). The T-80 hydrophilic-hydrophobic balance index was defined at 15 , which is known in producing a transparent oil in water mixture (O/W) (Ghosh et al. 2013; Qian and McClements 2011).

\section{FGEO-NE physical properties}

The Dynamic light scattering (DLS) method was utilized to estimate the droplets' Z-average as the FGEONE valid size index. Additional size approval tests were performed applying high-resolution atomic-force microscope (AFM), Field emission electron microscopy (FESEM), and transmission electron microscopy (TEM). The FESEM was carried out according to Hongwu Sun et al. protocol. Briefly, a thin layer of the FGEO-NE solution was dried and placed on the microscope glass gold-coated slide to be analyzed (Sun et al. 2012). The FGEO-NE stability was determined by applying two-step phases:

a) Droplets' size estimation every 4 days during 16-days storage at ambient temperature.

b) Droplets' surface zeta potential at $\mathrm{pH}=7$ (The 16-days version)

All samples were measured in triplicate manner.

\section{Cell culture}

The colon cancer cells (HT-29) and normal human foreskin fibroblasts (HFF) were cultured in RPMI and DMEM cell culture media (respectively) containing FBS (10\%), penicillin/streptomycin (1\%) in $5 \%$ $\mathrm{CO}_{2}$ incubator at $37^{\circ} \mathrm{C}$ and $95 \%$ humidity.

\section{MTT assay}

The FGEO-NE cytotoxicity on both HT-29 and HFF cells was studied by seeding $5 \times 10^{3}$ cells/well in a 96well culture and incubating for 24 hours. The cells were treated with different FGEO-NE concentrations $(0.5,1,2,4$, and $8 \mu \mathrm{g} / \mathrm{mL})$ for three incubation times $(24,48$, and 72 hours). The wells' culture medium was then refreshed by a fresh MTT $(5 \mathrm{mg} / \mathrm{mL})$-supplemented media and incubated for 4 hours at $37^{\circ} \mathrm{C}$. 
The second refreshment phase was carried out by substituting the DMSO-supplemented fresh media and mixing for 10 minutes. Finally, the plate reader spectrophotometer (Stat Fax 2100) was utilized to record the samples' absorbance at $570 \mathrm{~nm}$. The cells' viability was measured according to the following equation(Soltani et al. 2015; Sajjadi et al. 2019):

Cell viability $(\%)=\left(\right.$ Sample $_{\text {absorbance }} /$ Control absorbance $) \times 100$.

\section{Gene expression measurements}

Following the HT-29 treatment at different concentrations of FGEO-NE $(1.5,3$, and $4.5 \mu \mathrm{g} / \mathrm{mL})$ and 48 hours incubation, the cells were harvested to extract RNA utilizing the RNeasy Mini kit (Qiagen, Hilden, Germany). The samples' total RNA content was then triggered for synthesizing the cDNA libraries by the Quantitect Reverse Transcription kit (Qiagen, Hilden, Germany). The primer sets' sequence of target genes including Cas-3, Cas-9, BAX, Bcl-2, SOD, CAT, and VEGF were designed for CDNA amplification. The GAPDH gene was applied as the housekeeping gene (Tab. 1). Finally, the SYBR Green PCR Master Mix (Qiagen, Hilden, Germany) was applied for measuring a comparative Real time-PCR analysis (Beyrami et al. 2020). In order to perform the reaction, a mixture with a volume of $20 \mu$ including of Syber Green (10 $\mu \mathrm{L})$, specific primer $(2 \mu \mathrm{L})$, of CDNA $(1 \mu \mathrm{L})$ and DW $(7 \mu \mathrm{L})$ was prepared and analyzed by CFX-96 Biorad.

Table 1. The sequences of target primer sets (Cas-3, Cas-9, BAX, Bcl-2, VEGF, CAT, and SOD) and control (GAPDH) gene

\begin{tabular}{|c|c|c|}
\hline Gene & Forward & Reverse \\
\hline GAPDH & 5 GCAGGGGGGAGCCAAAACGGT 3 & 5 TGGGTGGCAGTGATGGCATGG 3 \\
\hline Cas-3 & $5^{\prime}$ CTGGACTGTGGCATTGAGAC $3^{\prime}$ & 5 ACAAAGCGACTGGATGAACC 3 \\
\hline Cas-9 & 5 CCAGAGATTCGCAAACCAGAGG $3^{\prime}$ & 5 GAGCACCGACATCACCAAATCC $3^{\prime}$ \\
\hline BAX & 5 TTTGCTTCAGGGTTTCATCCA $3^{\prime}$ & 5 CTCCATGTTACTGTCCAGTTCGT $3^{\prime}$ \\
\hline $\mathrm{Bcl}-2$ & 5 CATGTGTGTGGAGAGCGTCAAC $3^{\prime}$ & 5 CAGATAGGCACCCAGGGTGAT $3^{\prime}$ \\
\hline VEGF & 5 CTGCTGTCTTGGGTGCATTG $3^{\prime}$ & 5 TTCACATTTGTTGTGCTGTAG $3^{\prime}$ \\
\hline CAT & 5 CGTGCTGAATGAGGAACAGA $3^{\prime}$ & 5 AGTCAGGGTGGACCTCAGTG $3^{\prime}$ \\
\hline SOD & 5 CAGCATGGGTTCCACGTCCA $3^{\prime}$ & 5 CACATTGGCCACACCGTCCT $3^{\prime}$ \\
\hline
\end{tabular}

\section{Acridine orange/Propodium lodide (AO/PI) staining}

First, $1 \times 10^{6}$ cells/well in a 6-well culture plate was cultured and after 24 hours, the cells were treated with $1.5,3$, and $4 \mu \mathrm{g} / \mathrm{ml}$ of FGEO nanoemulsions. After 48 -hours of incubation, the cells were harvested and put separately on glass slides. The cells' staining was carried out by adding $1 \mu \mathrm{L}$ fluorescent staining solution containing AO $(100 \mu \mathrm{g} / \mathrm{mL})$ and $\mathrm{PI}(100 \mu \mathrm{g} / \mathrm{mL})$ to each cell suspension droplets $(25 \mu \mathrm{L})$ and 
then covered with a coverslip. The apoptotic cell morphology was studied utilizing a fluorescent microscope (OLYMPUS, Japan) (Khatamian et al. 2021).

\section{Murine colon cancer model}

This experiment was performed in full compliance with ethical principles and obtaining a code of ethics (IR.IAU.MSHD.REC.1399.070). Initially, 32 male Balb/C mice were purchased from Pasteur Institute of Iran and after transfer to the laboratory and adaptation to the new environment; cancer induction was done in each sample with injection of $100 \mu \mathrm{L}$ of CT-26 cell suspension $\left(3 \times 10^{5}\right)$ subcutaneously. After observing the tumors, the samples were treated (intraperitoneal injection) with different concentrations of the FGEONE once in every two days for 14 days, no treatment was performed in the control samples. Tumor size was measured on days of treatment using a digital caliper and after the 14th day, the samples were killed with chloroform and the tumors were removed and transferred to $10 \%$ formalin. Tumors after incision using microtome were stain and the obtained slides were examined by the pathologist.

\section{Statistics}

Utilizing SPSS 21 software the one-way ANOVA tests were applied for all statistical calculations. The pvalues ( $p$-value $<0.001$ ) were considered as statistically significant levels.

\section{Results}

GC-MS analysis

Data from the standard mass spectrum reported 51 components, accounting for $99.5 \%$ of the total frankincense essential oil (Table 2). Chromatogram results showed that alpha and beta-pinene accounted for about $17.9 \%$ and $58.5 \%$ of the total essential oil composition (respectively).

Table 2. Essential oil compounds obtained by GC-MS analysis 


\section{No. Compound}

1 a-Pinene,(1S)-2,6,6-Trimethylbicyclo[3.1.1]hept-2- ene

2 Camphene, Bicyclo[2.2.1]heptane, 2,2-dimethyl-3- methylene-, (1S)-

3 Cyclohexane, 1,1'-dodecylidenebis[4- methyl-

$4 \quad$ B-Pinene, Bicyclo[3.1.1]heptane, 6,6-dimethyl-2- methylene-, (1S)- Bicyclo[2.2.1]heptane,

2,2-dimethyl-3- methylene-, (1R)-

$5 \quad \beta$-Myrcene, $\beta$-Pinene, Bicyclo[3.1.1]heptane, 6,6-dimethyl-2- methylene-, (1S)-

6 Decane

7 3-Carene

8 Benzene, 1-methyl-3-(1-methylethyl), Benzene, 1-ethyl-2,4-dimethyl-

9 D-Limonene, Cyclohexene, 1-methyl-5-(1- methylethenyl)-, (R)-

10 a-Pinene, $\beta$-Ocimene

$11 \quad \beta$-Ocimene, 3-Carene

12 Cyclohexene, 1-methyl-4-(1- methylethylidene)-, Cyclohexene, 3-methyl-6-(1methylethylidene)-

13 Bicyclo[3.1.1]heptan-3-ol, 6,6-dimethyl-2- methylene-, [1S-(1a,3a,5a)]-,

Bicyclo[3.1.1] heptan-3-ol, 6,6-dimethyl-2- methylene-

14 Pinocarvone, Sabinone

15 (3E,5Z)-1,3,5-Undecatriene, (E,E)-1,3,5-Undecatriene, (3Z,5E)-1,3,5-Undecatriene, 5Undecen-3-yne, (E)-

16 (3Z,5E)-1,3,5-Undecatriene, 5-Undecen-3-yne, (E)-, (3E,5Z)-1,3,5-Undecatriene

17 Benzenemethanol, a, a,4-trimethyl-, m-Cymen-8-ol

18 (-)-Myrtenol, Bicyclo[3.1.1] hept-2-ene-2-methanol, 6,6- dimethyl-

19 trans-3-Caren-2-ol

20 Fenchyl acetate, a-FENCHYL ACETATE, Bicyclo[2.2.1] heptan-2-ol, 1,3,3-trimethyl-, acetate, (1S-exo)-

21 Benzene, 2-methoxy-1-methyl-4-(1- methylethyl)-, Benzene, 1-methoxy-4-methyl-2-(1methylethyl)-, Benzene, 2-methoxy-4-methyl-1-(1-methylethyl)-

22 3-Methylbut-2-enoic acid, 4-cyanophenyl ester, 3-Methylbut-2-enoic acid, 4-nitrophenyl ester, 1,5-Heptadien-4-one, 3,3,6-trimethyl-, 3-Methyl-2-butenoic acid, cyclobutyl ester

23 Bornyl acetate, Bicyclo[2.2.1]heptan-2-ol, 1,7,7-trimethyl-, acetate, (1S-endo)-, Acetic acid, 1,7,7-trimethyl-bicyclo[2.2.1] hept-2-yl ester, Bicyclo[2.2.1]heptan-2-ol, 1,7,7trimethyl-, formate, endo- 
25 4,7,7-Trimethylbicyclo[4.1.0]hept-3-en-2- one, 2-Cyclohexen-1-one, 3-methyl-6-(1methylethylidene)-

26 a-Terpinyl acetate

27 1,2,4-Metheno-1 H-indene, octahydro-1,7a -dimethyl-5-(1 methylethyl)-, [1S-

$\left.\left(1 a, 2 a, 3 a \beta, 4 a, 5 a, 7 a \beta, 8 S^{*}\right)\right]$, Ylangene

28 Copaene, Ylangene, a-Cubebene

29 Cyclohexane, 1-ethenyl-1-methyl-2,4-bis (1-methylethenyl)-, [1S-(1a,2 $\beta, 4 \beta)]$,

Cyclohexane, 1-ethenyl-1-methyl-2,4-bis (1-methylethenyl)-, Cyclohexane, 1-ethenyl-1-

methyl-2,4-bis (1-methylethenyl)-, (1a,2 $\beta, 4 \beta)$ -

30 1H-3a,7-Methanoazulene, octahydro-3,8,8 -trimethyl-6 methylene-, [3R-

$(3 a, 3 a \beta, 7 \beta, 8 a a)]-$, Cedrene, (3R,3aR,7R,8aS)-3,8,8-Trimethyl-6- methyleneoctahydro-1H$3 a, 7$, methanoazulene

31 2-(4a,8-Dimethyl-2,3,4,4a,5,6- hexahydronaphthalen-2yl)propan-1-ol,

Tetracyclo[6.1.0.0(2,4).0(5,7)] nonane,3,3,6,6,9,9 hexamethyl- $(1 a, 2 a, 4 a, 5 \beta, 7 \beta, 8 a)$ -

32 Isoledene, (1R,3aS,8aS)-7-Isopropyl-1,4-dimethyl- 1,2,3,3a,6,8a-hexahydroazulene

33 (3aR,4R,8R,8aS)-3a,4,8a-Trimethyl-7- methylenedecahydro-4,8-methanoazulene -rel

34 1,4,7,-Cycloundecatriene, 1,5,9,9- tetramethyl-, Z,Z,Z-Humulene

$35 \quad \mathrm{y}$-Muurolene

36 Naphthalene, decahydro-4a-methyl-1- methylene-7-(1-methylethenyl)-, [4aR-

$(4 a a, 7 a, 8 a \beta)]-$

37 2H-3,9a-Methano-1-benzoxepin, octahydro-2,2,5a,9-tetramethyl-, [3R- (3a,5aa,9a,9aa)]-, (3R,5aR,9S,9aS)-2,2,5a,9- Tetramethyloctahydro-2H-3,9a- methanobenzo[b]oxepine

38 Oxamide, N-(4-methobenzyl)-N'-(1- methylpropyl)-

39 Naphthalene, 1,2,3,5,6,8a-hexahydro-4,7- dimethyl-1-(1-methylethyl)-, (1S-cis)-, 1Isopropyl-4,7-dimethyl-1,2,3,5,6,8a- hexahydronaphthalene

$40 \quad(-)$-a-Panasinsen

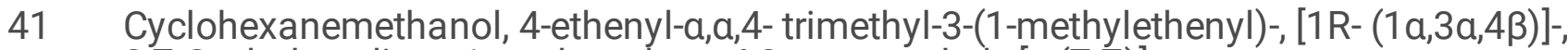

3,7-Cyclodecadiene-1-methanol, a,a,4,8- tetramethyl-, [s-(Z,Z)]

42 1,5-Cyclodecadiene, 1,5-dimethyl-8-(1- methylethylidene)-, (E,E)-

43 (-)-Spathulenol, 1H-Cycloprop[e]azulen-7-ol, decahydro- 1,1,7-trimethyl-4-methylene-,

[1 ar- $(1 \mathrm{aa}, 4 \mathrm{aa}, 7 \beta, 7 \mathrm{a} \beta, 7 \mathrm{ba})]$-, Isospathulenol

44 Junenol

45 5-Azulenemethanol, 1,2,3,4,5,6,7,8- octahydro-a,a,3,8-tetramethyl-, Guaiol

$46 \quad \beta$-Guaiene

47 2-((2S,4aR)-4a,8-Dimethyl- 1,2,3,4,4a,5,6,7, octahydronaphthalen-2- yl)propan-2-ol 

a-epi-7-epi-5-Eudesmol

50 5-Azulenemethanol, 1,2,3,4,5,6,7,8- octahydro-a,a,3,8-tetramethyl-

\section{FGEO-NE characterization}

The results of different formulations based on the amount of surfactant showed that the formulation containing $9 \%$ surfactant $(9 \mathrm{ml} \mathrm{T-80})$ has the smallest nanoparticle size (16-nm) with the acceptable dispersion index (0.530), which was considered as the selected formulation (Table. 3 ). Regarding the Steinfeld et al. findings, Nano emulsions with less than 0.7 PDI values show a mono-distribution formulation, which is required for the reliable Z-average values (Stetefeld et al. 2016).

Table 3. The FGEO-NE's droplet size in different formulation conditions; each measurement has been measured in triplicate manner $(\mathrm{N}=3)$.

\begin{tabular}{|lll|}
\hline T-80 volume $(\mathrm{ml})$ & Z-average $(\mathrm{nm})$ & PDI \\
\hline 3 & 86.1 & 0.491 \\
6 & 27.2 & 0.546 \\
9 & 16 & 0.530 \\
\hline
\end{tabular}

Examination of the samples stability during 16 days after storage showed an increase in particle size to $24.6 \mathrm{~nm}$ and a decrease in the dispersion index to 0.414 (Fig. 1A/left), which indicates the stability of the formed nanoparticles. In addition, the results of sample $\zeta$ potential showed that the FGEO-NE have a surface charge of $-28.5 \mathrm{mV}$, which according to the findings of previous studies; this value is within an acceptable range (-16 to $-30 \mathrm{mV}$ ) to confirm the stability of nanoparticles (Salopek et al. 1992). Also, the TEM, FESEM, and AFM analysis verify the droplets' size which had been measured by the DLS method (Fig. 1B, C). Examination of FGEO-NE morphology in TEM images shows particles with spherical, cylindrical and polyhedral morphology that according to the results of some studies, this morphology (Polymorphic) causes high efficiency of nanoparticles.

\section{FGEO-NE Cytotoxicity}

The cytotoxicity effect of FGEO-NE against HT-29 as a cancer cells in comparison with HFF as normal cells was investigated by MTT method. As shown in the diagram (right), the toxicity of FGEO-NE against HT-29 cells depends on concentration and time. The toxicity effect of FGEO-NE on HT-29 cells 24 hours after treatment shows that the lowest inhibition is observed at a concentration of $2 \mu \mathrm{L} / \mathrm{mL}(17 \%)$ and with increasing concentration to 4 and $8 \mu \mathrm{l} / \mathrm{ml}$, the inhibition increases to $45 \%$ and $97 \%$ (Fig. 1 right). The 
median concentration $\left(\mathrm{IC}_{50}\right)$ of FGEO-NE against cancer cells 24,48 and 72 hours after treatment was reported to be about 4.3, 2.9 and 1.08 (Table-4) that indicating the time-dependent cytotoxic effects of FGEO-NE. Evaluation of inhibition of HFF cells in treatment with different concentrations of FGEO-NE (0.5, 1,2 and $4 \mu \mathrm{L} / \mathrm{mL}$ ) did not show a significant difference with untreated cells. However, with increasing the treatment concentration to $8 \mu \mathrm{g} / \mathrm{mL}$, the inhibition rate increased above $90 \%$ in all three time efficiencies, indicating the concentration-dependent effects of FGEO-NE against normal cells (Fig. 1 left). Therefore, in this study, a concentration of 4 and $8 \mu \mathrm{L} / \mathrm{mL}$ of FGEO-NE were reported as a safe and toxic dose (respectively). Comparison of the FGEO-NE toxicity against normal and cancer cells confirmed the effect of its selective toxicity on cancer cells. This may be due to the complex diversity in cancer cell biochemical responses comparing with normal types. Moreover, high levels of metabolic activities in cancer cells make them vulnerable to cytotoxic compounds due to their involved antioxidant defense network.

Table 4. The $\mathrm{IC}_{50}$ values of FGEO-NE in colon cancer (HT-29) and normal (HFF) cell lines; each measurement has been measured in triplicate manner $(\mathrm{N}=3)$.

\begin{tabular}{|lll|}
\hline Incubation times & $\mathrm{IC}_{50}$ doses for HT-29 \\
$(\mu \mathrm{g} / \mathrm{mL})$ & $\begin{array}{l}\mathrm{IC}_{50} \text { doses for HFF } \\
(\mu \mathrm{g} / \mathrm{mL})\end{array}$ \\
\hline $24 \mathrm{~h}$ & 4.380 & 6.220 \\
\hline $48 \mathrm{~h}$ & 2.923 & 6.080 \\
\hline $72 \mathrm{~h}$ & 1.087 & 6.091 \\
\hline
\end{tabular}

\section{FGEO-NE and the HT-29 cell death type}

\section{HT-29 gene expression profile}

Following to HT-29 treatment with different concentrations of FGEO-NE, a significant up-regulation was detected for both anti-oxidant (CAT and SOD) and apoptotic (Cas-3, BAX, and Cas-9) gene expression. This is while the anti-apoptotic $\mathrm{Bcl}-2$ and angiogenic VEGF mRNA levels were faced with a meaningful down-regulation. The FGEO-NE treatment doses significantly lead to the CAT and SOD genes overexpression ( $p$-value $=<0.001$ ) (Fig. 3). On the other hand, the HT-29 gene expression profile reflects the induction of apoptosis pathways and suppression of angiogenesis response in cancer cells following FGEO-NE treatments. Therefore, FGEO-NE can simultaneously neutralize both cancer cell strategies, antiapoptosis and angiogenesis induction, despite of its cyto-protective impact (CAT and SOD up-regulating), which makes it appropriate to be used as an efficient anticancer therapeutic.

\section{Fluorescent $\mathrm{AO} / \mathrm{PI}$ staining}

Following to HT-29 treatment plane, the AO/PI stained HT-29 cells revealed a significant positive relationship between the number of apoptotic cells and FGEO-NE concentrations, which approves the 
successful apoptotic pathways in response to FGEO-NE treatment. Fig. 4 shows the occurrence of apoptosis in cells treated with FGEO-NE compared to untreated cells. In the control group, due to the infiltration of $\mathrm{AO}$ as a vital dye into healthy cells, most cells are green, while in FGEO-NE-treated samples, due to damage to the cell membrane, PI dye penetrated the damaged cells and caused to emitted red color in cells.

FGEO-NE anti-cancer potential in the murine colon cancer model

Fig. 5 shows images taken of tumor sections in two magnifications of 100 and 400 . As shown in Figure $5 A$ and $B$, in the control sample, the tumor tissue is uniform and no change is observed. In samples treated with different concentrations of FGEO-NE, some areas, which are seen more densely colored, show areas where the cells have undergone apoptosis and the tumor tissue is out of uniformity. As can be seen, the amount of apoptotic areas increases with increasing concentration of FGEO-NE and in samples treated with $100 \%$ FGEO-NE, apoptotic areas increased significantly and its cells are observed in dark color. Examination of tumor size in treated samples compared to control samples (Fig 5C) shows that the volume of tumors in control samples and samples treated with 50\% FGEO-NE concentration increased over time. In samples treated with $75 \%$ of FGEO-NE, an increase in tumor size was reported until the 5th day, while in the following days, tumor volume showed a decreasing trend, and this result shows the inhibitory effect of FGEO-NE on tumor volume. The inhibitory effect of 100\% FGEO-NE concentration on tumor size was observed from the first day of treatment. In fact, treatment with $100 \%$ FGEO-NE showed an inhibitory effect of about $69.7 \%$ on tumor growth.

\section{Discussion}

The increase in the incidence of colorectal cancer in humans and the lack of safe and effective treatments make the treatment of this disease face serious challenges (Fotheringham et al. 2019). In this regard, more targeted therapeutic strategies including nanocarrier systems to deliver bioactive compounds and drugs for more effective treatment of this disease have been used recently.

In this study, the chemical composition of Ferula gummosa essential oil (FGEO) was determined by chromatographic method and followed the FGEO was formulated to increase bioavailability and improve therapeutic properties in the nanoemulsion system. The results of chromatography showed that the highest percentage of essential oil ingredients is including $\beta$-Pinene, a-Pinene, Camphene, $\beta$-Myrcene, Decane, D-Limonene which is comparable to the compounds specified in Ferula gummosa and frankincense essential oil (Meshkatalsadat et al. 2013; Chen et al. 2013).

In this study, formulation optimization was investigated using different concentrations of surfactant and the smallest nanoparticles were obtained from a combination of $3 \%$ essential oil, $9 \%$ surfactant and $88 \%$ water by using ultrasonic method. Investigation the stability of nanoparticles after 16 days of storage confirmed a slight change in particle size $(24.6 \mathrm{~nm})$ and a decrease in the dispersion index (0.414). Investigation of zeta potential of nanoparticles reported the presence of repulsive force to prevent their agglomeration. Various methods are used to synthesize of nanoemulsions (Date et al. 2010; Navaei 
Shoorvarzi et al. 2020), Among these, ultrasonic method is known as a low-cost, clean, fast and easy method (Mahdi Jafari et al. 2006), so in this investigation, similar to the some previous studies (Anjali et al. 2012; Salvia-Trujillo et al. 2013; Mahdi Jafari et al. 2006; Kentish et al. 2008), this method was used to synthesize FGEO-NE.

The synthesis of nanoemulsions requires the presence of compounds called surfactants, which are active surface molecules that, due to their amphiphilic nature, reduce interfacial stress and cause dispersion of two immiscible phases (Kralova and Sjöblom 2009). Twin 80 surfactant is a non-ionic surfactant that has double bonds in its hydrocarbon chain, which makes it possible to form nanoparticles with smaller dimensions in the presence of this surfactant (Ghosh et al. 2014). Similar to the present study, in the synthesis of turmeric, basil, black seed and carvacrol nanoemulsions, T-80 was used as a surfactant(Periasamy et al. 2016). Particle size has a direct effect on their dispersion, stability and bioavailability (Kramer 2016). Smaller droplet size helps inhibit fouling and in addition affects the permeability of active compounds through vascular membranes and tissues and increases their bioavailability (Tharwat et al. 2004). The presence of nanoparticles with dimensions of $24.6 \mathrm{~nm}$ in this study indicates the efficiency of the formulation used. Similarly, in previous studies, different emulsions have been synthesized with nanometer dimensions from garlic oil (93.4 nm) (Mossa et al. 2018), eugenol oil (80 nm) (Abd-Elsalam and Khokhlov 2015), black seed oil (20-50nm) (Periasamy et al. 2016) and aniseed(198nm) (Hashem et al. 2018).

Evaluation of the FGEO-NE toxicity against HT-29 $\left(\mathrm{IC}_{50} 48 \mathrm{~h}: 2.92 \mu \mathrm{g} / \mathrm{ml}\right)$ compared to HFF $\left(\mathrm{IC}_{50} 48 \mathrm{~h}: 6.08\right.$ $\mu \mathrm{g} / \mathrm{ml}$ ) confirmed the selective inhibitory effects of FGEO-NE against cancer cells (HT-29). Similar to the present study, the toxicity of curcumin nanoemulsions synthesized using black pepper oil confirmed the effects of selective toxicity of nanoemulsions against cancer cells (HTh-7) compared to normal cells (Hek-293) (Nirmala et al. 2019)Similar results were obtained by Khatamian et al in 2019 using cumin nanoemulsion(Khatamian et al. 2019). In this study, it was shown that cumin nanoemulsion is able to inhibit normal and cancer cells with $\mathrm{IC}_{50}$ of $12.5 \mu \mathrm{g} / \mathrm{mL}$ and $50 \mu \mathrm{g} / \mathrm{mL}$, respectively, which indicates the effect of high toxicity of nanoemulsion on cancer cells.

Effective anti-cancer compounds must be able to inhibit cancer cells with minimal side effects on normal cells, and this inhibition can be achieved through various strategies such as apoptosis or suppression of angiogenesis(Safarzadeh et al. 2014). Escape from apoptosis is the most important strategy of cancer cells for survival and proliferation, so the induction of this process can prevent the proliferation and growth of malignant cells. Investigation of the effect of FGEO-NE on induction of apoptotic process showed that this compound increases the permeability of mitochondrial membrane by activating BAX and inhibiting BCL-2, and following led to the release of cytochrome $C$ and activation of caspase 9 and then caspase 3 (Elmore 2007; Sayers 2011). Therefore, it can be said that in this study, nanoemulsion induced apoptosis in treated cells through the internal pathway. Similarly, an increase in caspases 3 and 7 as caspases of the common apoptotic pathway in prostate cancer cells treated with curcumin nanoemulsion was shown in a 2011 study (Guan et al. 2017). Also, various studies have also reported an 
increase in caspase-3 in cancer cells treated with cumin essential oil nanoemulsion (Khatamian et al. 2019) and peanut oil nanoemulsion (Fazelifar et al. 2020).

The anti-tumor effects of FGEO-NE on inhibition of tumor growth in murine colon cancer model showed that FGEO-NE treatment, in addition to reducing the size of tumors, causes apoptotic and necrotic areas in tumor tissue, indicating its anticancer effect of FGEO-NE. Similar to the present study, in a study conducted in 2018, the pro-apoptotic effects of carvacrol nanoemulsion were confirmed via mitochondrial mediated apoptosis (Increase and decrease the expression of BAX and BCL-2 respectively), and very potent antitumor effects of this compound were reported in tumor-bearing mice (Khan et al. 2018). Similarly in 2016, the antitumor effects of Nano emulsion loaded with Piplartine $(10 \mathrm{mg} / \mathrm{kg})$ were reported in mice with melanoma tumor (Fofaria et al. 2016).

Angiogenesis is a process that occurs in tumors and helps them survive and multiply. Inhibition of this process stops the supply of nutrients needed by cancer cells and is an effective way to control cancer. Some anticancer drugs target cancer cells in this way (Gautam et al. 2014). Inhibition of vascular endothelial growth factor (VEGF), which plays an important role in angiogenesis, is a major indicator of the anti-angiogenic behavior displayed by nanoemulsions. In this study, as expected, treatment of cells with FGEO-NE reduced the expression of VEGF gene as the main gene involved in the angiogenesis process. These results were also confirmed in the study of the anti-angiogenic effect of betulin nanoemulsion (Dehelean et al. 2013). Also, in previous studies, the anti-angiogenic effect of nanoemulsion of lemon essential oil and memecylon was investigated and confirmed (Rekha et al. 2018) (Yousefian Rad et al. 2020). Also, our findings reflect the overexpression of the antioxidant gene (CAT and SOD) in HT-29 cancer cells, which is expected to be up-regulated in response to toxic compounds (Jelic et al. 2020). In other words, the increasing FGEO-NE treatment doses induce the CAT and SOD genes upregulation in HT-29 cells. This clearly reflects the improvement of HT-29 survival pathways following FGEO increasing concentrations. However, it is not dominant enough to prevent apoptosis in HT-29 cells.

\section{Conclusion}

In conclusion, Ferula gummosa essential oil nanoemulsion causes a significant cell-specific apoptotic death in HT-29 human colon cancer cells. It has also targeted two main cancer survival strategies including apoptotic suppression and angiogenesis induction in HT-29 colon cancer cells. Therefore, the FGEO-NE is suggested to be used as a cell-selective natural anticancer tool in human colon cancer therapy. However, there are still several apoptotic and angiogenic genes that have to be studied to detect its exact anticancer mechanism.

\section{Declarations}

Acknowledgments 
The authors very much appreciate the support provided by the Islamic Azad University, Mashhad, Iran, in the conducting of the present research.

\section{Conflict of interest}

The authors declare that there are no conflict of interest.

\section{Ethical Approval and Consent to participate}

This material has not been published in whole or in part elsewhere;

The manuscript is not currently being considered for publication in another journal;

All authors have been personally and actively involved in substantive work leading to the manuscript, and will hold themselves jointly and individually responsible for its content.

Ethical Approvalcode: IR.IAU.MSHD.REC.1399.070

\section{Authors' contributions}

Masoud Homayouni Tabrizi conceived of the presented idea. Toktam Nosrat, Ayda Etminan, Bahar Zarei, Amir Rahmati and Majoubeh Irani performed the experiments and computations. Masoud Homayouni Tabrizi verified the analytical methods.

\section{Funding}

This research received no specific grant from any funding agency in the public, commercial, or not-forprofit sectors.

\section{References}

1. Abd-Elsalam KA, Khokhlov AR (2015) Eugenol oil nanoemulsion: antifungal activity against Fusarium oxysporum f. sp. vasinfectum and phytotoxicity on cottonseeds. Appl Nanosci 5(2):255265

2. Anjali C, Sharma Y, Mukherjee A, Chandrasekaran N (2012) Neem oil (Azadirachta indica) nanoemulsion-a potent larvicidal agent against Culex quinquefasciatus. Pest Manag Sci 68(2):158-163

3. Azadmehr A, Hajiaghaee R, Afshari A, Amirghofran Z, Refieian-Kopaei M, Yousofi Darani H, Shirzad H (2011) Evaluation of in vivo immune response activity and in vitro anti-cancer effect by Scrophularia megalantha. J Med plants Res 5(11):2365-2368

4. Benelli G, Pavela R, Canale A, Cianfaglione K, Ciaschetti G, Conti F, Nicoletti M, Senthil-Nathan S, Mehlhorn H, Maggi F (2017) Acute larvicidal toxicity of five essential oils (Pinus nigra, Hyssopus 
officinalis, Satureja montana, Aloysia citrodora and Pelargonium graveolens) against the filariasis vector Culex quinquefasciatus: Synergistic and antagonistic effects. Parasitol Int 66(2):166-171

5. Beyrami M, Karimi E, Oskoueian E (2020) Synthesized chrysin-loaded nanoliposomes improves cadmium-induced toxicity in mice. Environ Sci Pollut Res 27(32):40643-40651

6. Chen Y, Zhou C, Ge Z, Liu Y, Liu Y, Feng W, Li S, Chen G, Wei T (2013) Composition and potential anticancer activities of essential oils obtained from myrrh and frankincense. Oncol Lett 6(4):11401146

7. Date AA, Desai N, Dixit R, Nagarsenker M (2010) Self-nanoemulsifying drug delivery systems: formulation insights, applications and advances. Nanomedicine 5(10):1595-1616

8. Dehelean CA, Feflea S, Gheorgheosu D, Ganta S, Cimpean AM, Muntean D, Amiji MM (2013) Antiangiogenic and anti-cancer evaluation of betulin nanoemulsion in chicken chorioallantoic membrane and skin carcinoma in Balb/c mice. J Biomed Nanotechnol 9(4):577-589

9. Elmore S (2007) Apoptosis: a review of programmed cell death. Toxicol Pathol 35(4):495-516

10. Fazelifar P, Tabrizi MH, Rafiee A (2020) The Arachis hypogaea Essential Oil Nanoemulsion as an Efficient Safe Apoptosis Inducer in Human Lung Cancer Cells (A549).Nutrition and Cancer:1-9

11. Fofaria NM, Qhattal HSS, Liu X, Srivastava SK (2016) Nanoemulsion formulations for anti-cancer agent piplartine-Characterization, toxicological, pharmacokinetics and efficacy studies. Int J Pharm 498(1-2):12-22

12. Fotheringham S, Mozolowski GA, Murray EM, Kerr DJ (2019) Challenges and solutions in patient treatment strategies for stage II colon cancer. Gastroenterol Rep 7(3):151-161

13. Gautam N, Mantha AK, Mittal S (2014) Essential oils and their constituents as anticancer agents: a mechanistic view. BioMed research international 2014

14. Ghosh V, Mukherjee A, Chandrasekaran N (2014) Eugenol-loaded antimicrobial nanoemulsion preserves fruit juice against, microbial spoilage. Colloids Surf B 114:392-397

15. Ghosh V, Saranya S, Mukherjee A, Chandrasekaran N (2013) Cinnamon oil nanoemulsion formulation by ultrasonic emulsification: investigation of its bactericidal activity. $\mathrm{J}$ Nanosci Nanotechnol 13(1):114-122

16. Guan Y-b, Zhou S-y, Zhang Y-q, Tian Y-d, Jia Y-y, Sun Y-j (2017) Therapeutic effects of curcumin nanoemulsions on prostate cancer. J Huazhong Univ Sci Technol [Medical Sciences] 37(3):371-378

17. Hashem AS, Awadalla SS, Zayed GM, Maggi F, Benelli G (2018) Pimpinella anisum essential oil nanoemulsions against Tribolium castaneum-insecticidal activity and mode of action. Environ Sci Pollut Res 25(19):18802-18812

18. Jelic MD, Mandic AD, Maricic SM, Srdjenovic BU (2020) Oxidative stress and its role in cancer

19. Kadioglu O, Seo EJ, Efferth T (2013) Targeting angiogenesis by phytochemicals. Med Aromat Plants 2(5):1-8

20. Kentish S, Wooster T, Ashokkumar M, Balachandran S, Mawson R, Simons L (2008) The use of ultrasonics for nanoemulsion preparation. Innovative Food Science \& Emerging Technologies 
9(2):170-175

21. Khan I, Bahuguna A, Kumar P, Bajpai VK, Kang SC (2018) In vitro and in vivo antitumor potential of carvacrol nanoemulsion against human lung adenocarcinoma A549 cells via mitochondrial mediated apoptosis. Sci Rep 8(1):1-15

22. Khatamian N, Homayouni Tabrizi M, Ardalan P, Yadamani S, Darchini Maragheh A (2019) Synthesis of Carum Carvi essential oil nanoemulsion, the cytotoxic effect, and expression of caspase 3 gene. $J$ Food Biochem 43(8):e12956

23. Khatamian N, Soltani M, Shadan B, Neamati A, Tabrizi MH, Hormozi B (2021) Pinus morrisonicola needles essential oil nanoemulsions as a novel strong antioxidant and anticancer agent.Inorganic and Nano-Metal Chemistry:1-9

24. Kosmo DdF, AVALIAÇÃO DA CITOTOXICIDADE DA FASE VAPOR DO ÓLEO ESSENCIAL DE Jasminum officinale EM CALU-3 (2017) (ADENOCARCINOMA DE PULMÃO) E 3T3 (FIBROBLASTOS).

25. Kralova I, Sjöblom J (2009) Surfactants used in food industry: a review. J Dispers Sci Technol 30(9):1363-1383

26. Kramer S (2016) Recent Advances in Gold-Catalyzed Intermolecular Aryl C- H Functionalization. Chemistry-A Eur J 22(44):15584-15598

27. Mahboubi M (2016) Ferula gummosa, a traditional medicine with novel applications. J Diet supplements 13(6):700-718

28. Mahdi Jafari S, He Y, Bhandari B (2006) Nano-emulsion production by sonication and microfluidization-a comparison. Int J Food Prop 9(3):475-485

29. Meshkatalsadat M, Salhvarzi S, Aminirad R (2013) Chemical Composition of Volatile Oil from Ferula gummosa using Hydrodistillation Profile.MH29 (1)

30. Mitoshi M, Kuriyama I, Nakayama H, Miyazato H, Sugimoto K, Kobayashi Y, Jippo T, Kanazawa K, Yoshida H, Mizushina Y (2012) Effects of essential oils from herbal plants and citrus fruits on DNA polymerase inhibitory, cancer cell growth inhibitory, antiallergic, and antioxidant activities. J Agric Food Chem 60(45):11343-11350

31. Mossa A-TH, Afia SI, Mohafrash SM, Abou-Awad BA (2018) Formulation and characterization of garlic (Allium sativum L.) essential oil nanoemulsion and its acaricidal activity on eriophyid olive mites (Acari: Eriophyidae). Environ Sci Pollut Res 25(11):10526-10537

32. Navaei Shoorvarzi S, Shahraki F, Shafaei N, Karimi E, Oskoueian E (2020) Citrus aurantium L. bloom essential oil nanoemulsion: Synthesis, characterization, cytotoxicity, and its potential health impacts on mice. J Food Biochem 44(5):e13181

33. Nirmala MJ, Durai L, Gopakumar V, Nagarajan R (2019) Anticancer and antibacterial effects of a clove bud essential oil-based nanoscale emulsion system. Int J Nanomed 14:6439

34. Nishitani Yukuyama M, Tomiko Myiake Kato E, Lobenberg R, Araci Bou-Chacra N (2017) Challenges and future prospects of nanoemulsion as a drug delivery system. Curr Pharm Design 23(3):495-508 
35. Nobili S, Lippi D, Witort E, Donnini M, Bausi L, Mini E, Capaccioli S (2009) Natural compounds for cancer treatment and prevention. Pharmacol Res 59(6):365-378

36. Pavoni L, Benelli G, Maggi F, Bonacucina G (2019a) Green nanoemulsion interventions for biopesticide formulations. Nano-Biopesticides Today and Future Perspectives. Elsevier, pp 133-160

37. Pavoni L, Pavela R, Cespi M, Bonacucina G, Maggi F, Zeni V, Canale A, Lucchi A, Bruschi F, Benelli G (2019b) Green micro-and nanoemulsions for managing parasites, vectors and pests. Nanomaterials 9(9):1285

38. Pavoni L, Perinelli DR, Bonacucina G, Cespi M, Palmieri GF (2020) An Overview of Micro-and Nanoemulsions as Vehicles for Essential Oils: Formulation, Preparation and Stability. Nanomaterials 10(1):135

39. Periasamy VS, Athinarayanan J, Alshatwi AA (2016) Anticancer activity of an ultrasonic nanoemulsion formulation of Nigella sativa L. essential oil on human breast cancer cells. Ultrason Sonochem 31:449-455. doi:https://doi.org/10.1016/j.ultsonch.2016.01.035

40. Perlatti B, de Souza Bergo PL, Fernandes JB, Forim MR (2013) Polymeric nanoparticle-based insecticides: a controlled release purpose for agrochemicals. In: Insecticides-Development of safer and more effective technologies. IntechOpen

41. Qian C, McClements DJ (2011) Formation of nanoemulsions stabilized by model food-grade emulsifiers using high-pressure homogenization: factors affecting particle size. Food Hydrocolloids 25(5):1000-1008

42. Rekha N, Nagesha DK, Rajasree P, Shruthi N, FORMULATION, CHARACTERIZATION AND EVALUATION OF ANTI-INFLAMMATORY AND ANTI-ANGIOGENIC ACTIVITIES OF MEMECYLAENE NANOEMULSION (2018). Journal of Drug Delivery and Therapeutics 8 (5-s):126-131

43. Safarzadeh E, Shotorbani SS, Baradaran B (2014) Herbal medicine as inducers of apoptosis in cancer treatment. Adv Pharm Bull 4(Suppl 1):421

44. Sajjadi M, Karimi E, Oskoueian E, Iranshahi M, Neamati A (2019) Galbanic acid: Induced antiproliferation in estrogen receptor-negative breast cancer cells and enhanced cellular redox state in the human dermal fibroblasts. J Biochem Mol Toxicol 33(11):e22402

45. Salopek B, Krasic D, Filipovic S (1992) Measurement and application of zeta-potential. Rudarskogeolosko-naftni zbornik 4(1):147

46. Salvia-Trujillo L, Rojas-Graü A, Soliva-Fortuny R, Martín-Belloso O (2013) Physicochemical characterization of lemongrass essential oil-alginate nanoemulsions: effect of ultrasound processing parameters. Food Bioprocess Technol 6(9):2439-2446

47. Sayers TJ (2011) Targeting the extrinsic apoptosis signaling pathway for cancer therapy. Cancer immunology, immunotherapy 60 (8):1173-1180

48. Shafaei N, Barkhordar SMA, Rahmani F, Nabi S, Idliki RB, Alimirzaei M, Karimi E, Oskoueian E (2020) Protective effects of Anethum graveolens Seed's oil Nanoemulsion against cadmium-induced oxidative stress in mice. Biol Trace Elem Res 198(2):583-591 
49. Soltani M, Parivar K, Baharara J, Kerachian MA, Asili J (2015) Putative mechanism for apoptosisinducing properties of crude saponin isolated from sea cucumber (Holothuria leucospilota) as an antioxidant compound. Iran J basic Med Sci 18(2):180

50. Stetefeld J, McKenna SA, Patel TR (2016) Dynamic light scattering: a practical guide and applications in biomedical sciences. Biophys Rev 8(4):409-427

51. Sun H, Liu K, Liu W, Wang W, Guo C, Tang B, Gu J, Zhang J, Li H, Mao X, Zou Q, Zeng H (2012) Development and characterization of a novel nanoemulsion drug-delivery system for potential application in oral delivery of protein drugs. Int J Nanomedicine 7:5529-5543. doi:10.2147/IJN.S36071

52. Tharwat T, Izquierdo P, Esquena J, Solans C (2004) Formation and stability of nano-emulsions. Adv Colloid Interface Sci 9:108-109

53. Yousefian Rad E, Homayouni Tabrizi M, Ardalan P, Seyedi SMR, Yadamani S, Zamani-Esmati P, Haghani Sereshkeh N (2020) Citrus Lemon essential oil nanoemulsion (CLEO-NE), a safe celldepended apoptosis inducer in human A549 lung cancer cells with anti-angiogenic activity.Journal of Microencapsulation (just-accepted):1-24

\section{Figures}



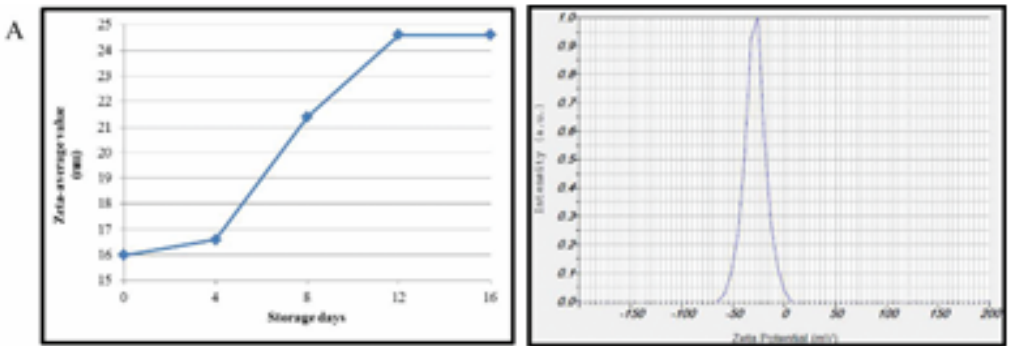

B
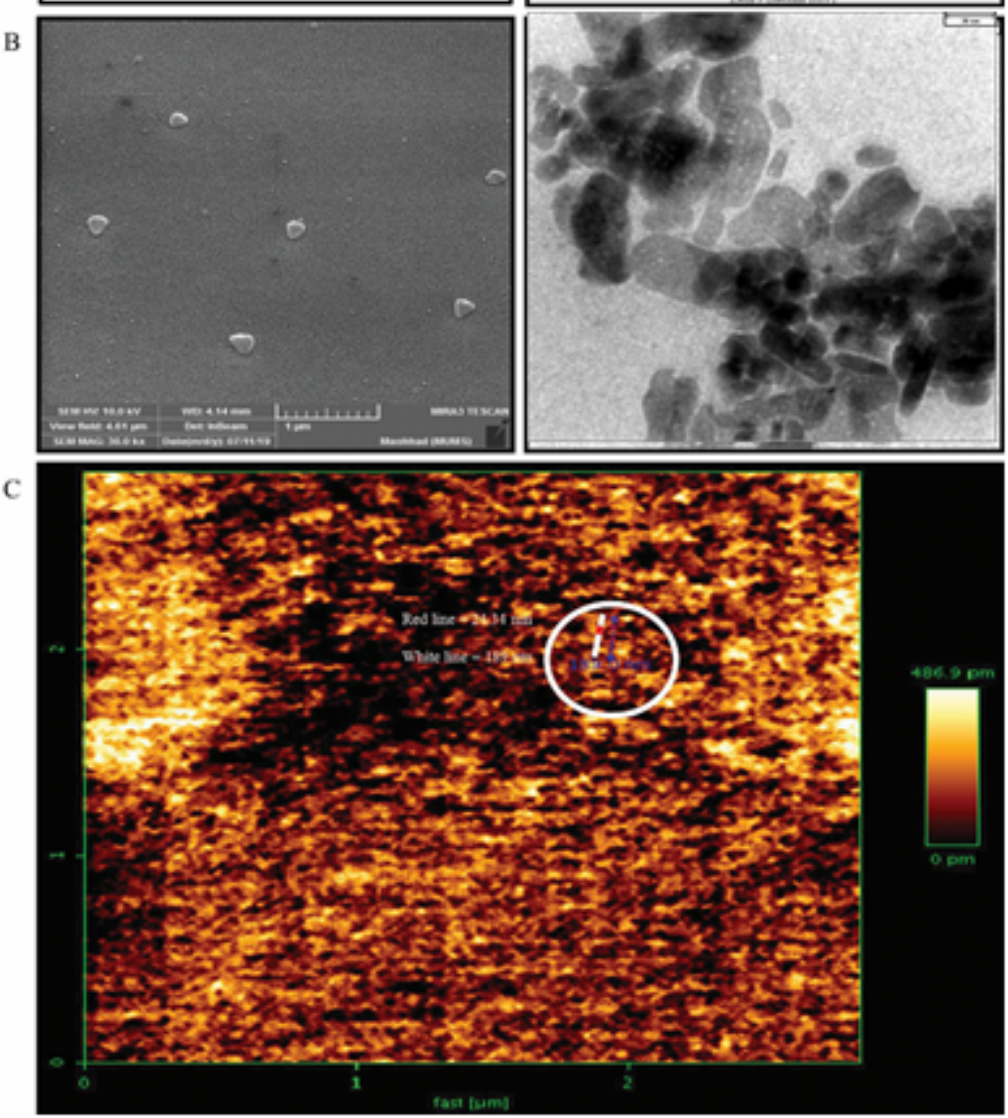

\section{Figure 1}

The FGEO-NE characterization data; A/left: The FGEO-NE size measurement during 16-days storage. $\mathrm{A} /$ right: The droplets surface charge (zeta potential) is at $-28.5 \mathrm{mV}$. B/left: FESEM image shows the single and agglomerated nano-droplets (scale bar: $1 \mu \mathrm{m}$ ). B/right: TEM image of the FGEO-NE (scale bar: $30 \mathrm{~nm}$ ). C: The white line has $189 \mathrm{~nm}$ lengths and its small internal red line shows the FGEO-NE droplet diameter ( 24.34 nm). 

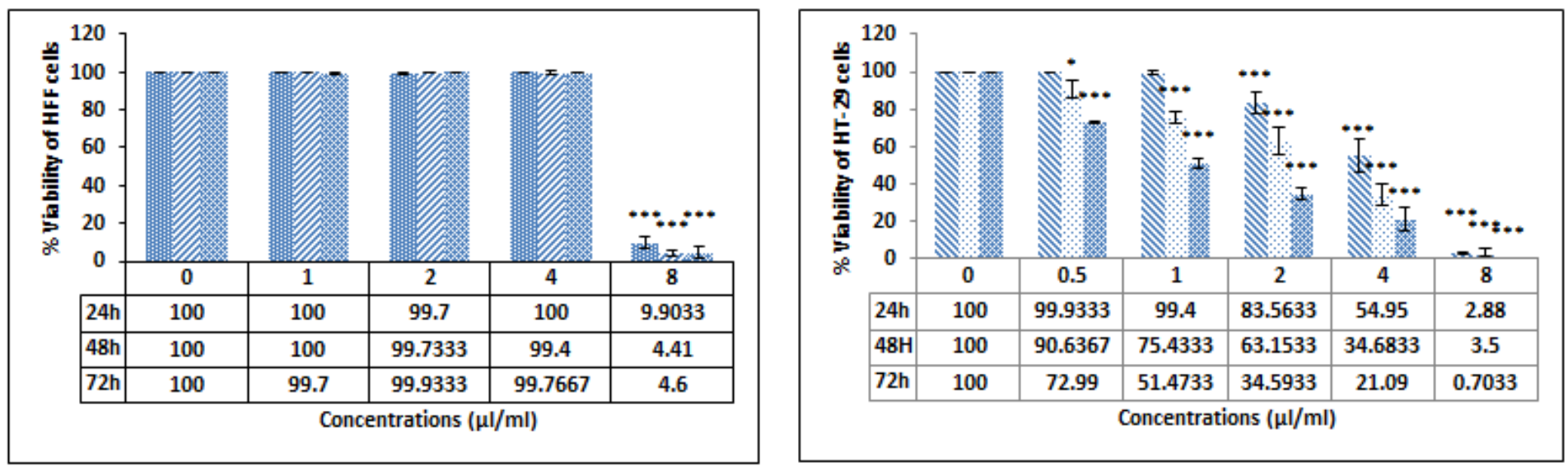

Figure 2

The FGEO-NE cytotoxic impacts on both colon cancer (HT-29) and normal (HFF) cell lines. The charts refer the cells viability percent under different FGEO-NE treatment doses $(8,4,2$, and $1 \mu \mathrm{g} / \mathrm{mL})$. The "*: and “ $\star \star \star$ "indicate the level of statistical significance ( $p$-Value $<0.05$ and $p$-Value $<0.001)$.

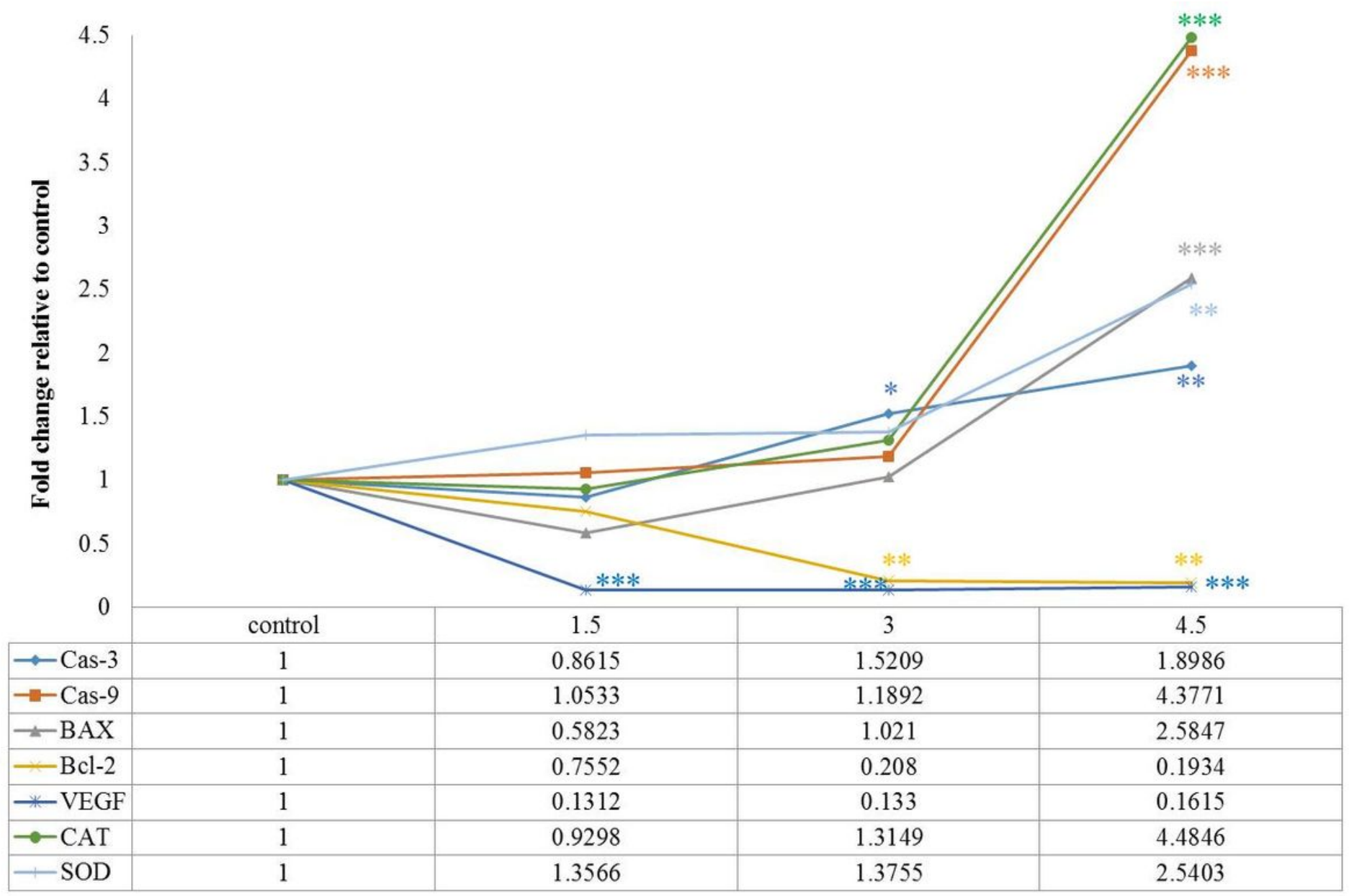

Concentration $(\mu \mathrm{g} / \mathrm{ml})$ 


\section{Figure 3}

The HT-29 colon cancer cell line gene expression profile. The fold changes values refer to the significant overexpression of Cas-3, cas-9, BAX, CAT, and SOD. This is while the Bcl-2 and VEGF genes have been

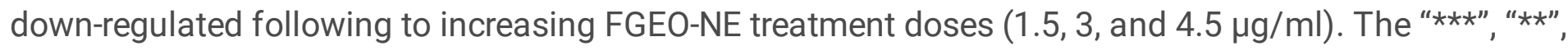
and " $*$ " indicate the $p$-Values $<0.001,<0.01$, and 0.05 , respectively).
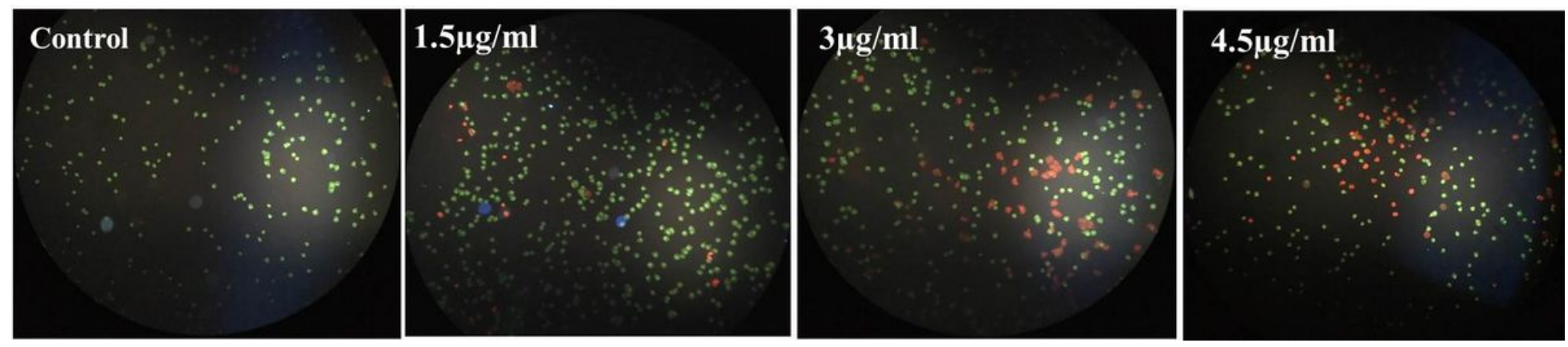

\section{Figure 4}

AO/PI fluorescent staining of the HT-29 colon cancer cells. The apoptotic dead and normal alive cells have been shown with orange and green colors, respectively. Following to increasing treatment doses of FGEO-NE $(1.5,3$, and $4.5 \mu \mathrm{g} / \mathrm{ml})$ the numbers of apoptotic dead HT-29 cells have significantly increased. 

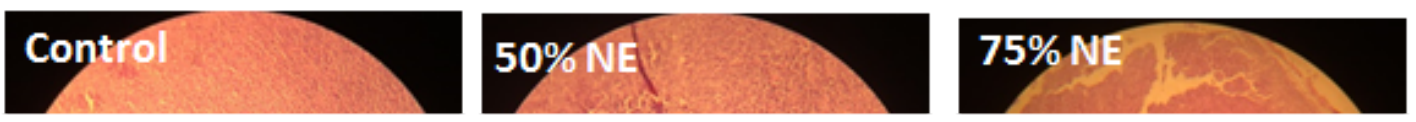

$100 \%$ NE

\section{Figure 5}

Inhibitory effects of FGEO-NE on tumor growth in a mouse model of colon cancer. Histopathological results of tumors isolated from control and treated specimens at $100(\mathrm{~A})$ and 400 (B) magnifications. Tumor volume changes in treated samples compared with controls (C). The sample of tumor-bearing mouse (D). 